\title{
Capitalismo e racionalidade instrumental: reflexões acerca do tempo livre em Theodor Adorno ${ }^{1}$
}

\author{
André Campos Rocha
}

\begin{abstract}
Resumo: $\mathrm{O}$ artigo analisa a relação entre trabalho e tempo livre no capitalismo segundo as reflexões sociológicas de Theodor W. Adorno. Defende-se que o tema é indissociável do diagnóstico contido na Dialética do Esclarecimento acerca da predominância, no desenvolvimento social do Ocidente, de uma razão de tipo instrumental. Neste contexto, com sua separação da esfera do trabalho, as atividades de tempo livre, paródias da liberdade, serviriam ao objetivo funcional de recuperar as forças dos sujeitos para reintroduzi-los no processo de trabalho. Ao final, mostra-se porque a arte para Adorno contém um potencial de crítica à sociedade reificada.
\end{abstract}

Palavras-chave: tempo livre; Theodor W. Adorno; reificação; teoria crítica.

\section{Capitalism and instrumental rationality: reflections on free time in Theodor Adorno}

\begin{abstract}
The article analyzes the relation between work and free time in capitalism according to the sociological reflections of Theodor W. Adorno. It is argued that the theme is inseparable from the diagnosis contained in the Dialectic of Enlightenment about the predominance in the social development of the West of an instrumental reason. In this context, with their separation from the sphere of work, free-time activities, parodies of freedom, would serve a functional goal of restoring the laborial forces of the subjects in order to reintroduce them intho the work process. In the end, it is shown why art for Adorno contains a critical potential within the reified society.
\end{abstract}

Keywords: free time; Theodor W. Adorno; reification; critical theory.

\footnotetext{
${ }^{1}$ Recebido em 23/01/18 e aprovado em 04/05/18.

${ }^{2}$ Bacharel em Ciências Sociais pela UFMG, mestrando em Sociologia pela USP. E-mail: videco230@hotmail.com
} 


\section{Capitalismo y racionalidad instrumental: reflexiones acerca del tiempo libre en Theodor Adorno}

Resumen: El artículo analiza la relación entre trabajo y tiempo libre en el capitalismo según las reflexiones sociológicas de Theodor W. Adorno. Se defiende que el tema es indisociable del diagnóstico contenido en la Dialéctica del Esclarecimiento acerca de la predominancia, en el desarrollo social de Occidente, de una razón de tipo instrumental. En este contexto, con su separación de la esfera del trabajo, las actividades de tiempo libre, parodias de la libertad, servirían al objetivo funcional de recuperar las fuerzas de los sujetos para reintroducirlos en el proceso de trabajo. Al final, se muestra porque el arte para Adorno contiene un potencial de crítica a la sociedad reificada.

Palabras clave: tiempo libre; Theodor W. Adorno; reificación; teoría crítica.

\section{Dialética do Esclarecimento: racionalidade instrumental e história}

Em seu livro, Dialética do Esclarecimento, Adorno e Horkheimer tecem o diagnóstico de que a racionalidade do esclarecimento - tal como realizada ao longo da história contém uma ambiguidade fundamental. Associada à corrente de pensamento iluminista do século XVIII, seu objetivo primordial era ressaltar a vocação racional do homem, sua liberdade inata e sua habilidade de desvendar os mistérios do mundo ao seu redor. Pautado por um ideal progressista, o pensamento esclarecido se colocou, desde o princípio, como um oponente ao pensamento mítico, fruto de uma visão do mundo que atribuía à natureza - e às coisas em geral - propriedades místicas e supramundanas. Diante de tal irracionalidade, baseada em um medo ancestral do homem em relação à onipotência das forças naturais, a razão esclarecida se estabeleceria como um princípio superior e autônomo, necessário ao homem para dominar aquelas forças e se transformar em senhor do mundo e de seu próprio destino (WILSON, 2007).

Segundo os autores, em seu intento de se separar do mito, o esclarecimento, por força de uma contradição dialética, é vítima de um processo que o enreda novamente nele. A tese central do livro 
aponta justamente para esse infortúnio: “o mito já é esclarecimento e o esclarecimento acaba por reverter à mitologia" (ADORNO; HORKHEIMER, 1985, p.15). Assim, por um lado, o pensamento mítico já contém traços do esclarecimento em seu intento de conhecer os poderes naturais:

\begin{abstract}
Mas os mitos que caem vítimas do esclarecimento já eram o produto do próprio esclarecimento [...] O mito queria relatar, denominar, dizer a origem, mas também expor, fixar, explicar. Com o registro e a coleção dos mitos, esta tendência reforçou-se (ADORNO; HORKHEIMER, 1985, p. 20).
\end{abstract}

Por outro lado, o esclarecimento converte-se em mito. O pensamento científico positivista, que surgiu como consequência da tentativa esclarecida de dominar a natureza, deve expulsar dela aquelas múltiplas forças demoníacas de um universo habitado por espíritos e convertê-la a um princípio único e indivisível, objetivo; isto é, a natureza mesma. Esta, no entanto, transforma-se em mera objetividade, ocasionando a dissolução das diferenças específicas dos objetos mundanos, extirpadas para que a razão triunfante cumpra eficientemente sua pretensão de domínio. Todos os fenômenos naturais são reduzidos a uma unidade fundamental para que sejam controlados e manipulados; é o que acontece, por exemplo, ao cientista no laboratório, para quem todos os ratos são iguais, pois portadores das mesmas propriedades físico-químicas, do mesmo modo que para o engenheiro é indiferente se o mesmo sal mineral provém de uma montanha brasileira ou chinesa.

A racionalidade do esclarecimento, ao reduzir a natureza a uma objetividade inerte, adquire, ela mesma, este caráter de objetividade. Trata-se de sua transformação no que passou a ser nomeado pelos autores da primeira geração da Teoria Crítica de "racionalidade instrumental", de tipo estratégico, isto é, um tipo de pensamento calculador que procura a todo instante maximizar os ganhos e minimizar as perdas, em uma incessante busca de adaptação dos melhores "meios" para se alcançar determinados 
"fins". Assim, não só a natureza é reduzida a uma série de eventos calculáveis, enquanto a subjetividade, por seu turno, convertese em uma máquina de cálculo, dominada por uma técnica que supostamente realizaria o ideal de liberdade do homem. Por vezes, Adorno e Horkheimer a designam pelo termo ratio, o mesmo que Weber (1987) emprega para explicitar as bases do chamado "espírito do capitalismo", afirmando que no capitalismo ocidental a razão se associa cada vez mais às ideias de "cálculo", "contabilidade" e "cômputo".

Segundo os autores "o esclarecimento exprime o movimento real da sociedade burguesa como um todo sob o aspecto da encarnação de sua Ideia em pessoas e instituições..." (ADORNO; HORKHEIMER, 1985, p.13). Isto implica que, nesta sociedade, as ações humanas adquirem certa previsibilidade e as instituições sociais, marcadas pela racionalidade instrumental, ganham vida própria, funcionam sob uma lógica que, de certa forma, se descola da atividade reflexiva dos sujeitos que as perpetuam. Além disso, encarnada nas pessoas, a razão instrumental se converte no modo pelo qual os sujeitos irão efetivamente se socializar na sociedade capitalista, em uma lógica adaptativa em relação à configuração das relações sociais tais como elas se apresentam. Quem não agir estrategicamente em uma sociedade individualista e competitiva - na qual a apropriação de recursos materiais e simbólicos é conquistada ao preço da eliminação dos concorrentes - está fadado ao constante risco de fracassar e perecer.

Ora, de acordo com Adorno e Horkheimer (1985), a razão instrumental, enquanto mecanismo de autopreservação do sujeito, é também autodestrutiva, uma vez que ela entrega mais do que recebe. Restringida a um meio de garantir a sobrevivência, tornase irracional, uma vez que a vida reduzida a mera necessidade carece de completude e, no íntimo, todos nós ansiamos por uma existência plena de sentido, por uma vida que efetivamente "valha a pena" de ser vivida. Assim, os homens pagam um preço muito alto ao longo do chamado processo civilizatório (FREUD, 1978). $\mathrm{O}$ "Eu" moderno, idêntico a si mesmo, é constituído através da abjuração de seus impulsos imediatos em prol da garantia de sua 
existência, de modo que "a história da civilização é a história da introversão do sacrifício - a história da renúncia". (ADORNO; HORKHEIMER, 1985, p.85)

A tese sustentada pelos autores acerca da progressiva racionalização da sociedade tem como pano de fundo um entretecimento cada vez mais complexo das relações sociais, onde cada indivíduo adquire uma função específica dentro da estrutura social. É só agora, sugerem Adornoe Horkheimer, que o "conceito de sociedade", referente a uma "espécie de contextura formada entre todos os homens [...] a cada um dos quais se atribui, em princípio, uma tarefa funcional," "atingiu seu pleno desenvolvimento, na fase de socialização total da humanidade." (ADORNO; HORKHEIMER 1973, p. 26) No contexto de uma divisão racional do trabalho, este é diligentemente separado de seu contrário, o prazer, e pesa como um fardo sobre a vida dos homens. A mescla de trabalho rotinizado e uma subjetividade tomada pela razão de autoconservação esboça o infortúnio do homem na sociedade moderna: "A absoluta solidão, o retorno forçado ao próprio eu, cujo ser se reduz a elaboração de um material no ritmo monótono do trabalho, delineam como um espectro horrível a existência do homem no mundo moderno." (ADORNO; HORKHEIMER 1985, p.186) O trabalho, como bem observou Marx (1978), transforma-se em mercadoria; ou seja, como produtor de valor, constitui-se em um simples meio através do qual o trabalhador garante sua subsistência, consumando um processo de exteriorização, mortificação e negação da própria vida.

Enquanto instrumento, e não como um fim em si mesmo, determina a priori o status vivente dos submetidos. Ora, se a caracterização do trabalho enquanto mercadoria é pertinente para Adorno, a assunção de que a ordem social baseada neste princípio tende à desintegração - uma recôndita esperança de Marx - foi desmentida historicamente: o que ocorreu foi a expansão irrestrita do sistema capitalista e de sua lógica social pautada em relações de troca abstratas, cujas tendências antagônicas foram dirimidas pela atividade consciente e planejada do Estado (RUGITSKY, 2008; POLLOCK, 1978). Segundo Pollock (1978), nas décadas de 30 e 40 do século $\mathrm{XX}$ o capitalismo estaria passando por transformações 
estruturais que colocavam o automatismo das leis de mercado em xeque impedindo, ao mesmo tempo, o colapso do sistema ${ }^{3}$. Com efeito, a interferência do Estado nas questões econômicas, dirimindo as tendências disruptivas do sistema, abriria a possibilidade de certa planificação econômica no seio mesmo do capitalismo. Este diagnóstico histórico, apontando para o surgimento de uma espécie de "capitalismo de Estado" (em suas variantes democráticas e totalitárias), será condensado por Adorno e Horkheimer, em um sentido mais filosófico e sociológico, no conceito de "mundo administrado", isto é, um mundo social hermético e fechado em si mesmo, sem possibilidade de fuga, restando aos sujeitos reproduzirem suas vidas sob o princípio intransparente do trabalho mercantilizado. Neste ínterim, o trabalho se transforma em um princípio negativo enquanto tal, quase que uma ontologia negativa da sociedade baseada na troca. Segundo Adorno:

Só enquanto o processo, que se implanta com a transformação da força de trabalho em mercadoria, se impõe a todos os homens sem exceção, reifica e torna ao mesmo tempo comensurável a priori cada um dos seus movimentos num jogo de relações de troca, é possível que a vida se reproduza sob as relações de produção dominantes. A sua total organização exige a união dos mortos. A vontade de viver vê-se remetida para a negação da vontade de viver: a auto-conservação anula a vida na subjetividade (ADORNO, 2001, p. 223)

\footnotetext{
${ }^{3}$ Segundo Pollock, o capitalismo de Estado se baseia, sobretudo, em quatro princípios. Em primeiro lugar, a economia é sujeita a um plano geral, que dá as diretrizes da produção, do consumo, da poupança e do investimento. Em segundo, os preços tem a possibilidade de serem administrados. Em terceiro, a motivação do lucro de indivíduos e grupos persiste, mas agora estritamente subordinada ao plano geral. Finalmente, todas as esferas de atividade do Estado (expandindo-se para a esfera social) são submetidas aos princípios da administração científica, elaborando-se sistematicamente, desde cima, todos os processos. Daí, apaziguadas as incertezas quanto aos fins dados aos recursos disponíveis, os problemas e os conflitos da sociedade se deslocam para a esfera política. (POLLOCK, 1978)
} 


\section{O tempo livre no mundo administrado}

Estes dois temas, a dependência cada vez maior dos indivíduos dos laços sociais e a monotonia do processo de trabalho na era industrial, também estão presentes, de uma forma ou de outra, nas reflexões teóricas dos outros dois pais fundadores da sociologia, Weber e Durkheim, acerca da especificidade do capitalismo em relação a épocas anteriores da história humana. No entanto, em nítido contraste com a atitude resignada - ou mesmo apologética do status quo - discernível em suas formulações teóricas, o marxismo se constituiu, desde seus momentos iniciais, como uma crítica da sociedade capitalista, almejando uma reflexão teórica que vislumbrasse as possibilidades efetivas da superação da alienação no âmbito do trabalho. Neste sentido, em sua conferência Capitalismo tardio ou sociedade industrial? de fins da década de 60, Adorno (1986) antecipa sua posição pessimista quanto à possibilidade de superação de uma ordem social heteronômica, afirmando que o conceito de capitalismo permanece válido e que, no seio de relações de produção coaguladas e coisificadas, a esfera econômica continua a exercer sua dominação sobre os homens. Mesmo que naquele estágio histórico do capitalismo o aumento da produtividade tenha possibilitado a diminuição da jornada de trabalho, a liberdade continuaria sendo ilusória. Assim, sob tais circunstâncias, se se quisesse responder à questão do que ocorre com o tempo livre:

[...] tornar-se-ia imperiosa a suspeita de que [ele] tende
em direção contrário à seu próprio conceito, tornando-
se paródia deste. Nele prolonga-se a não liberdade, tão
desconhecida da maioria das pessoas não livres como
a sua não-liberdade em si mesma (ADORNO, 1995, p.
71).

Como sugere Musse (2016), a conferência-ensaio de Adorno sobre o tempo livre se configura como uma "atualização e como um comentário das considerações de Marx acerca da situação do 
trabalho no capitalismo tardio" (p. 107), consistindo, ao mesmo tempo, em um diagnóstico histórico da realidade social produzida por uma sociedade dominada pela razão instrumental.

A questão do tempo livre não pode ser formulada "em generalidade abstrata", ou seja, deve ser investigada levando-se em conta os traços característicos do regime de trabalho no sistema capitalista. A tese de Adorno segundo a qual a sociedade é um sistema ecoa no fato de que até nos momentos em que os sujeitos pensam estar libertos do trabalho estão, na verdade, acorrentados a ele:

\begin{abstract}
A questão do tempo livre [...] não pode ser formulada em generalidade abstrata. A expressão [...] aponta a uma diferença específica que o distingue do tempo não livre, aquele que é preenchido pelo trabalho, e, poderíamos acrescentar, determinado desde fora. O tempo livre é acorrentado ao seu oposto. Esta oposição, a relação em que ela se apresenta, imprime-lhe traços essenciais. (ADORNO, 1995, p.70) [grifo meu]
\end{abstract}

Como vimos, em uma época de integração social sem precedentes, onde cada pessoa assume uma função específica dentro do todo segundo o cumprimento de um papel social, mesmo aquele rincão da vida onde os seres humanos creem agir por vontade própria está marcado por aquilo que eles desejam se ver livres fora do horário de trabalho. De fato, uma das características distintivas da sociedade burguesa é uma divisão rígida entre o tempo dedicado ao trabalho e aquele destinado às atividades de lazer e diversão. Sob este ordenamento racional, próprio ao modo de vida das sociedades industriais modernas, a experiência deve ser organizada com zelo puritano; qualquer rebeldia do espírito, qualquer insistência no prazer, é suspeita aos olhos do espírito dominante. Segundo Adorno, esta separação se cristalizou de tal modo no consciente e no inconsciente dos homens que ela tem consequências nefastas para ambos os momentos. Em seus comentários críticos a respeito da obra de Oswald Spengler, $A$ decadência do Ocidente, Adorno diz que Spengler: 
vê com [...] exatidão o estado de consciência que se apodera das massas fora do processo de produção propriamente dito, ao qual elas estão atreladas: os fenômenos costumeiramente designados como pertencendo ao tempo livre. 'A tensão intelectual, conhece apenas uma forma de descanso, aquela que é específica da metrópole: o relaxamento, a distração...' (ADORNO, 1998, p.46)

Ora, a citação acima indica uma oposição clara entre tensão intelectual e relaxamento, significando que: por um lado, no trabalho, atividade que deve ser levada a sério, os indivíduos despendem suas energias físicas e intelectuais na consecução de uma atividade produtiva; e, por outro, nos períodos de descanso, que não devem lembrar em nada o trabalho, a atividade dos sujeitos toma a forma de um alívio, de um esquecimento das tensões produzidas pela vida acachapante do cotidiano, e, não por acaso, elas são dotadas de algo supérfluo e fútil, cumprindo o imperativo funcional de preparar os sujeitos para serem reinseridos, com energias renovadas, no processo de trabalho. Porque eminentemente crítica, afeita à ressignificação das práticas do próprio sujeito, a reflexão seria como que um possível disruptor da situação de adaptação e, por isso mesmo, se a segurança emocional inerente a uma situação conformista quiser perdurar, ela não pode ir muito longe:

Nenhuma satisfação pode ser inerente ao trabalho que, aliás, perde a sua modéstia funcional na totalidade dos fins, nenhuma faísca da reflexão pode irromper durante o tempo livre, porque poderia saltar para o mundo do trabalho e pô-lo em chamas (ADORNO, 2001, p. 122).

Segundo Adorno, através da imposição das pressões sociais do capitalismo a maioria das pessoas se sujeitaria a um esquema temporal específico, refletindo uma disposição psicológica neurótica, que pode ser interpretada, nos termos da "psicologia 
profunda", pelo conceito de sintoma bifásico. Trata-se de um dispositivo psicológico internalizado pelos sujeitos em sua lide com as exigências contraditórias impostas pela realidade objetiva, de tal modo que o conflito inerente entre os impulsos instintuais e as pressões sociais é apaziguado pela transformação destas relações eminentemente excludentes em relações de precedência. $\mathrm{Na}$ experiência concreta dos sujeitos, isto se traduz em um mecanismo de recompensa, no qual: "o prazer transforma-se na recompensa pelo trabalho e o trabalho expiação do prazer". Nesta reiteração cotidiana da relação dialógica de expiação e anulação, institucionaliza-se uma tendência obsessiva denominada "comportamento bifásico":

[...] o paciente comporta-se ora como se fosse criança travessa, ora como disciplinador severo e primitivo. Por motivos obsessivos, certo paciente não conseguia escovar os dentes e, passado algum tempo, batia em si mesmo, ralhava consigo mesmo. Outro trazia sempre uma agenda em que anotava o que tinha feito para indicar louvor ou censura. (FENlCHEL apud ADORNO, 2008, p. 97)

O caráter ideológico da coluna de astrologia do Los Angeles Times é que ela traveste estas tendências patológicas, fruto de padrões sociologicamente condicionados, em dados naturais e invariáveis, como se fossem verdades últimas da vida humana. Sob a influência desta hipóstase, Adorno sugere que a diversão e o entretenimento adquirem um caráter compulsivo, isto é, são constantemente recomendados pelos veículos de publicidade, como no caso das dicas presentes na coluna que aconselham um aproveitamento eficaz do tempo: na parte da manhã, "dedique-se ao trabalho", à tarde, "sinta-se livre para divertir-se" (ADORNO, 2008). Isto conflui para o aparecimento de um tipo de ideologia especificamente moderna, a saber, a ideologia do hobby, que cristaliza a idéia de reificação das práticas de lazer indicando, ao mesmo tempo, seu caráter mercantil: 
Na naturalidade da pergunta sobre qual 'hobby' se tem está subentendido que se deve ter um, porventura, também já escolhido de acordo com a oferta do negócio do 'tempo livre'. Liberdade organizada é coercitiva: Ai de ti se não tens um 'hobby'! [...] Tal coação de nenhum modo é exterior, ela se liga às necessidades das pessoas sob um sistema funcional. [...] (ADORNO, 1995: p.74)

Assim, a coisificação do trabalho se reflete na coisificação das atividades de tempo livre, as quais, em uma sociedade dominada pelo capital, são frequentemente subsumidas pelo jugo das forças econômicas. Neste contexto, situa-se a já conhecida tese de Adorno acerca do conluio das tendências culturais contemporâneas com a sociedade subjugada pela razão instrumental. Os produtos da indústria cultural (meticulosamente produzidos e distribuídos por grandes organizações econômicas sob a regra geral das relações de troca) nada mais fazem do que articular a necessidade subjetiva das pessoas por lazer com as da indústria em geral, inculcandolhes, mediante cálculo de efeitos, certa disposição compulsória ao consumo. E, precisamente por sua futilidade, seus produtos apenas denunciam uma rendição acrítica ao status quo:

\begin{abstract}
A própria necessidade de liberdade é funcionalizada e reproduzida pelo comércio. Por isso, a integração do 'tempo livre' é alcançada sem maiores dificuldades; as pessoas não percebem o quanto não são livres lá onde mais livres se sentem, porque a regra de tal ausência de liberdade foi abstraída delas. (ADORNO, 1995, p.74)
\end{abstract}

\title{
3. Inversão meios e fins: o fetiche do trabalho
}

Proponho, aqui, que voltemos a um dos tópicos centrais da Dialética do Esclarecimento para compreendermos porque a sociedade capitalista é uma sociedade bloqueada, cujos membros perderam a capacidade de se emanciparem. Como vimos, no desenvolvimento social do Ocidente há uma espécie de fetichização da razão instrumental. Diluindo-se seu sentido 
objetivo, ligado às mais altas aspirações humanas desde a filosofia grega, a razão se identifica progressivamente com a ideia de cálculo, tornando-se um mecanismo de adaptação aos processos sociais e, concomitantemente, perdendo a aptidão de entrever os fins últimos da atividade humana em sociedade (HORKHEIMER, 2015).

Nesta sociedade, o valor das coisas costuma ser julgado estritamente por critérios de utilidade. O "útil" relaciona-se à razão instrumental, de autoconservação, orientada pela busca dos mais eficientes meios disponíveis para assegurar a sobrevivência humana. $\mathrm{O}$ "inútil", por outro lado, resplandece além da esfera da mera necessidade, e inclui os elementos da vida cultural cuja única justificativa é que eles justificam tudo o mais, pertencendo a uma esfera da vida na qual o uso não possui nenhuma força normativa ou lógica. Liga-se a uma razão substantiva, cuja significação é a própria realização da ideia de liberdade, de algo que é por si só, em nítido contraste com a natureza da razão instrumental voltada para o aperfeiçoamento dos meios sob a égide de uma força de domínio. Ora, aquelas duas formas de razão seriam complementares, já que o telos do esclarecimento seria a consumação da razão em algo substantivo, preparando os alicerces de uma vida social na qual abundariam atividades culturais não produtivas e alheias aos interesses materiais do homem. Em uma sociedade verdadeiramente racional a razão serviria à liberdade do homem (MORGAN, 1988).

Adorno sempre pensou a questão da emancipação em termos da abolição da lei do trabalho e do desfrute desinteressado das dádivas da natureza. Conforme aponta Jay (1984), a teoria do valor-trabalho nunca foi central para ele, o qual, em nítido contraste com Lukács, rejeitou a ideia de que a emancipação é função "de uma prática coletiva não alienada baseada no poder de criação de valor do trabalho". Refletindo uma ética burguesa "o trabalho não pode ser hipostasiado de forma alguma, nem sob a forma do labor manual, nem sob a forma da produção intelectual. Uma tal hipóstase dá prosseguimento apenas à ilusão da predominância do princípio produtivo" (ADORNO, 2009, p. 271). Além disso, apesar 
de sua recusa em evocar a imagem da utopia, encontramos, entre as poucas sugestões a este respeito, passagens em Minima Moralia em que Adorno fornece um retrato de um mundo emancipado no qual as coisas perderiam seu véu de utilidade e a autêntica felicidade seria possível sob a abolição da lei do trabalho:

A casa, à criança que regressa das férias, parece-lhe nova, fresca, festiva. Mas nada nela mudou, desde que a deixara. O simples fato de esquecer as obrigações, que cada móvel, cada janela, cada lâmpada lhe recorda, restitui a estes sua paz sabática... Não de outro modo surgirá o mundo [...] à perpétua luz de sua festividade, e para quem regressa a casa as obrigações são tão fáceis como o jogo nas férias. (ADORNO, 2001, p. 102)

Rien faire comme une bête [Não fazer nada como um animal] flutuar na água e olhar pacatamente para o céu, "nada mais ser, sem outra determinação ou plenitude", poderia substituir o processo, o fazer, o cumprir, tornando assim efetiva a promessa da lógica dialética de desembocar na sua origem. (ADORNO, 2001, p. 149)

Como vimos, se essa era a aspiração inicial do esclarecimento, a sociedade burguesa criada à sua imagem resplandece sob o infortúnio de que aquela relação foi invertida, ou seja, sob as condições sociais atuais a racionalidade instrumental se tornou um fim em si, ao passo que a racionalidade gratuita do inútil converteuse em meio, desempenhando uma função prática no mundo. Em sua investigação sobre a correlação entre as concepções religiosas protestantes e o surgimento do "espírito do capitalismo", Weber expõe como em um mundo desencantado um tipo de ethos profissional, moldando uma conduta racional e metódica de vida, se apodera da consciência dos homens. Livre de suas conotações religiosas, esta ética vem a se tornar um imperativo de adaptação sob as pressões sociais e econômicas da ordem social capitalista, sendo que todo caráter eudaimonista e hedonista da vida - o gozo, 
o ócio, a contemplação - ou mesmo a simples perda de tempo são condenados como uma espécie de esquecimento do dever, consumando-se uma inversão de uma relação natural do homem consigo mesmo e com o mundo externo a ele. (WEBER, 1987, p.33)

Isto conflui para o diagnóstico de que em tal sociedade o trabalho e a produção material são fetichizados, tornam-se fins em si mesmos, efetivando uma divisão racional do trabalho cujo resultadoé a separação rígida do fazer e do pensar, do trabalho físico e do trabalho intelectual. O lazer e o entretenimento, capturados pelo campo de força da racionalidade econômica, convertem-se em necessidades funcionais, meios de alívio e regeneração das forças laborais; ou seja, em meros apêndices do trabalho. Deste modo, Adorno pode dizer que, nas condições atuais, o tempo livre nunca cumpre o que promete. A teoria de Schopenhauer segundo a qual o tédio, produto inexorável do nunca satisfeito apetite da cega vontade, seria uma espécie de condição original da espécie humana não deveria assim ser hipostasiada. O tédio é apenas o reflexo de uma vida coagida por uma rigorosa divisão do trabalho. Se as pessoas fossem livres, se pudessem determinar suas vidas de maneira autônoma, ele simplesmente não se instalaria e o domingo nos é penoso porque o vislumbre de emancipação se mescla com sua imediata negação:

A nostalgie du dimanche não é a nostalgia da semana laboral, mas deste estado de emancipação; o domingo deixa insatisfeito, não porque nele se festeje, mas porque a sua promessa não se apresenta ao mesmo tempo como imediatamente cumprida; como o inglês, todo domingo é demasiado pouco. Aquele para quem o tempo penosamente se alonga, espera em vão, frustrado de que o domingo persista, que amanhã seja outra vez como ontem (ADORNO, 2001, p.166).

\section{A arte enquanto crítica à sociedade administrada}

Segundo Jay (1984), se as melancólicas reflexões de Adorno em sua análise do mundo administrado levam ao reconhecimento 
da impossibilidade de uma possível resistência ao sistema enquanto totalidade - cuja expressão histórica se encontra no malogro do proletariado em fazer a revolução - há em suas reflexões, contudo, um apelo à resistência teórica e artística no nível micrológico. Voltando-se à chamada superestrutura da sociedade, a qual ocupou grande parte de sua reflexões, é que, sugere Jay, encontraríamos um potencial crítico à sociedade capitalista pautada pelas relações abstratas de troca.

Com efeito, o marxismo ortodoxo da II Internacional, colocando ênfase na infraestrutura material - o conjunto das forças produtivas e das relações de produção - preteriu os elementos superestruturais da sociedade, considerados meros epifenômenos da base material e, por isso, indignos de atenção. Levando-se em conta a revalorização do "cultural" pela tradição do "Marxismo Ocidental"4, caberia mostrar, brevemente, a importância da estética filosófica para a Teoria Crítica enquanto uma teoria da razão (BERNSTEIN, 2008).

No âmbito da reflexão filosófica prevaleceu, desde Platão, a ideia de uma dualidade entre razão e sentidos. Para Kant - e para Habermas em certa medida - a razão formal e científica constituiria o espaço próprio da liberdade, da normatividade, onde a vontade humana não poderia se subordinar aos cegos imperativos da causalidade natural. Inversamente, Nietzsche concebe esta razão formal e abstrata sob o signo da decadência, propugnando, contra sua frieza, uma vida orientada aos aspectos autocriadores e autoexpressivos próprios à dimensão estética da existência. Ao cabo, estas duas posições são espelhos uma da outra, pois acatam, mesmo que em polos opostos, a dicotomia razão/sentidos.

A primeira geração da Teoria Crítica nega que a razão e os sentidos pertençam a domínios completamente apartados e incomensuráveis da experiência. Ela afirma que o sensível é o outro reprimido e repudiado da razão, não no sentido de uma alternativa radical, mas como uma parte repudiada e, portanto, separada da razão. Assim, razão sem sensação é deformada e

${ }^{4}$ ver MERLEAU-PONTY 2006 
deformadora, e as questões estéticas pertencem intrinsecamente ao domínio da razão.

Vimos que no processo de racionalização do Ocidente as regras sociais se tornam cada vez mais abstratas e as ações sociais previsíveis e objetificadas. No capitalismo, o modelo prototípico desse processo é a subordinação crescente dos valores de uso aos valores de troca; a predominância do trabalho abstrato, consubstanciado na forma valor, sobre as relações humanas concretas (MARX, 1983). Neste contexto, uma razão dominadora da natureza, esquematizadora dos processos da vida, restringe as potencialidades da experiência humana a formas acabadas, objetificadas e racionais, relegando o contextual, o contingente e o sensível ao domínio inócuo da estética. A reapropriação deste domínio corresponderia então ao estudo da razão integral em sua forma alienada: "protesto da razão socialmente determinada contra sua forma instrumental ressequida." (BERNSTEIN, 2008, p. 183)

Tomando como ponto de partida as reflexões acima, podemos explorar mais detidamente o caráter crítico da arte para Adorno. Primeiramente, cabe dizer que, para ele, a arte, enquanto expressão da independência do estético em relação a outras esferas da vida, carece de uma definição conceitual precisa porque ela é produto de um movimento histórico, dialético, definindose justamente em relação ao que ela "não é". Ou seja, embora se origine do mundo empírico, dele se afasta no momento em que se constitui como algo autônomo:

A arte só é interpretável pela lei de seu movimento, não por invariantes. Determina-se na relação. $O$ caráter específico que nela existe deve deduzir-se, quanto ao seu conteúdo, do seu Outro; apenas isto bastaria para qualquer exigência de uma estética materialista dialética (ADORNO, 2002, p. 3, tradução nossa)

Assim, a arte é social e não o é: ela está em uma relação de tensão com a sociedade da qual, no entanto, ela faz parte. Daí, diz 
Adorno, a autonomia da arte tem um caráter duplo (PETRY, 2014). Por um lado, negativamente, ela é autônoma no sentido de que se desvincula de suas funções sociais reguladoras associadas à política, à religião e à moral. Por outro, positivamente, ela passa a ser orientada por leis internas de desenvolvimento, por normas íntimas à sua atividade, circunscrevendo um campo de liberdade próprio em sua recusa em participar do mundo empírico do qual se originou. É justamente neste momento de afirmação positiva que reside sua importância crítica, já que em um contexto funcional marcado pela fungibilidade de todo e qualquer objeto em sua adequação para cumprir funções sociais preestabelecidas, a arte opõe-se a esta fungibilidade por se constituir como objeto único e insubstituível. Deste modo, enquanto específica forma de práxis pautada pelo desinteresse e pela gratuidade, a arte se constitui como um protesto contra o status quo, ao nos redirecionar a tarefas aparentemente sem nenhum propósito, fazendo recordar que a felicidade reside além da práxis instrumental e da necessidade de reprodução material - de acordo com o mote kantiano, "finalidade sem fim":

Cristalizando-se em si mesma como algo único para si mesmo, ao invés de obedecer às normas sociais existentes e qualificar-se como socialmente útil, ela critica a sociedade meramente por existir [...] A não sociabilidade da arte é a negação determinada de uma sociedade determinada (ADORNO, 2002, p. 225-226, tradução nossa)

Assim, Adorno rejeita apelos artísticos que se pretendem abertamente políticos, pois a intenção de cumprir alguma função social trai o expediente crítico da arte em relação à sociedade. Ele entende que, pese os esforços que isto acarreta, a arte deve manter sua autonomia, isto é, não deve pretender dar nada, como se ela fosse uma espécie de investimento passível de oferecer algo a quem a aprecie. Isto não só a remeteria ao contexto empírico das necessidades práticas, como também se basearia na falsa pressuposição de que o significado linguístico pretendido pelas 
obras de arte é imediatamente disponível e transmissível aos receptores. Em Commitment (1962), um ensaio crítico à literatura politicamente comprometida defendida por Sartre, Adorno diz:

Aqueles que cantam louvores aos 'laços de ligação' [da linguagem] provavelmente irão achar mais profundo 'Entre quatro paredes' de Sartre que ouvir pacientemente a um texto no qual a linguagem balança a gaiola do significado e através de sua distância dele se rebela, desde o início, contra um pressuposto positivo de sentido (ADORNO, 1962, p. 2, tradução nossa)

A arte opõe-se ao real não pela explícita declaração de opiniões políticas, mas por meio de sua mera existência como arte. Isto, obviamente, tem a consequência de que sua autonomia - sua resistência a qualquer forma de cooptação - é comprada ao preço de seu progressivo enclausuramento em formas herméticas e fechadas, de difícil apreensão à nível social, com o efeito paradoxal de que, apesar de suas intenções críticas, ela adquire um caráter inofensivo:

Se a arte cede a sua autonomia, ela se entrega às maquinações do status quo; não obstante, se a arte se mantém estritamente para si mesma, ela é submetida à integração como um domínio inofensivo entre outros (ADORNO, 2002: p. 237, tradução nossa)

Se esta é uma aporia para a qual Adorno aparentemente não vê saída, ela toca em um ponto caro a sua concepção de que a arte deve estar além da compreensão conceitual, ou, em suas palavras, "na situação atual, haveria que apreender a sua ininteligibilidade". Neste sentido, justifica-se sua simpatia ao desafio que algumas correntes do modernismo artístico colocam às noções artísticas tradicionais, seja na música atonal de Schönberg (1874-1951), na poesia de Baudelaire (1821-1867) ou nas peças teatrais aparentemente sem sentido de Samuel Beckett (1906-1989).

Este isolamento das obras de arte do contexto societário faz vislumbrar uma superação das antinomias que conformam a 
experiência dos sujeitos na sociedade administrada. Como vimos, Adorno argumenta que uma das mais importantes condições de possibilidade da indústria cultural é uma demarcação rígida entre "consumo irrefletido" e "reflexão atenta", entre um espaço destinado às atividades sérias e centradas e outro ao relaxamento e à distração. O que a arte autônoma faz é precisamente questionar aquelas oposições, pois plasma um tipo de experiência onde prazer e pensamento, seriedade e futilidade, razão e sensibilidade se misturam. Na medida em que arte escapa das leis sérias que prevalecem na realidade (que nos dizem a todo instante que o mundo é duro e díficil) e não pode de nenhum modo ser subsumida a elas, remete ao desfrute e ao prazer e, neste sentido, é desinteressada. Por outro lado, como sugere uma fuga do mundo tal como ele se apresenta, ela contém a sugestão de que é possível outro tipo de realidade existir e, assim, forçando o pensamento a explorar novas possibilidades do real, ela é séria e comprometida (WILSON, 2007). Pertence, portanto, ao domínio da verdade, denunciando a falsidade subjacente às formas de entretenimento da indústria cultural, as quais, na medida em que são bens de consumo destinados tão somente a matar o tempo, desaparecendo do curso do mundo logo depois de usadas, assemelham-se a qualquer outra mercadoria, não deixando atrás de si nada de significativo.

\section{Referências}

ADORNO, T. W. Commitment. [S.1][s.n] 1962. Disponível em: $<$ https:ada.evergreen.edu/ arunc/texts/frankfurt/commitment/ commitment.pdf> Último acesso em: 28 de ago. 2017, 22:08.

ADORNO. T. W. Capitalismo tardio ou sociedade industrial? In: COHN, G. (org.) Theodor W. Adorno. São Paulo: Ática, 1986.

ADORNO, T. W. Tempo Livre. In: Palavras e sinais: modelos críticos 2. Petrópolis, RJ: Vozes, 1995.

ADORNO, T. W. Spengler após o declínio. In: Prismas. São Paulo: Ed. Ática, 1998. 
ADORNO, T. W. Minima Moralia. Lisboa, Portugal: Edições 70, 2001.

ADORNO, T. W. Aesthetic Theory. New York: Continuum, 2002.

ADORNO, T. W. As estrelas descem a Terra: a coluna de astrologia do Los Angeles Times. São Paulo: Unesp, 2008.

ADORNO, T. W. Dialética Negativa. Rio de Janeiro: Zahar, 2009.

ADORNO, T. W.; HORKHEIMER, M. Temas básicos de sociologia. São Paulo: Cultrix, 1973.

ADORNO, T. W.; HORKHEIMER, M. Dialética do Esclarecimento: fragmentos filosóficos. Rio de Janeiro: Jorge Zahar Ed. 1985.

BERNSTEIN, J. M. O discurso morto das pedras: a Teoria Estética de Adorno. In: RUSH, Fred (org.) Teoria Crítica. Aparecida, SP: Idéias\& Letras, 2008.

FREUD, S. O mal-estar na civilização. In: Os pensadores. São Paulo: Abril Cultural, 1978.

HORKHEIMER, M. O eclipse da razão. São Paulo: Unesp, 2015. JAY, M. Marxism and totality. L.A: UCLA Press, 1984.

MARX, K. Manuscritos econômico-filosóficos. São Paulo: Abril Cultural, 1978.

MARX, K. O capital. São Paulo: Abril Cultural, 1983.

MERLEAU-PONTY, M. As aventuras da dialética. São Paulo: Martins Fontes, 2006.

MORGAN, W. J. Adorno on Sport: The case of fractured dialetics. Theory and Society, Vol 17, N 6, 1988.

MUSSE, R. Administração do tempo livre. São Paulo: Revista Lua Nova, 99, 2016.

PETRY, F.B. A relação dialética entre arte e sociedade em Theodor W. Adorno. Revista Veritas, v.59, 2014. 
POLLOCK, F. State capitalism: Its possibilities and Limitations. In: The essencial Frankfurt School Reader. New York: New Urizon Books, 1978.

RUGITSKY, F. Friedrich Pollock - Limites e possibilidades. In: Curso livre de Teoria Crítica/ Marcos Nobre (org.) - Campinas, SP: Papirum 2008.

WEBER, M. A ética protestante e o espírito do capitalismo. São Paulo: Pioneira, 1987.

WILSON, R. Theodor Adorno. New York: Routledge critical thinkers, 2007. 
